\title{
Utilization of molecular and morphometric tools for assessment of genetic diversity of Rice bean [Vigna umbellata (Thunb.) Ohwi and Ohashi]
}

\author{
V. S. Meena ${ }^{1 *}$, R. K. Mittal ${ }^{2}$, P. R. Choudhury ${ }^{1}$, S. Rathod ${ }^{3}$, \\ H. K. Mahadevaswamy ${ }^{4}$ and R. Choudhary ${ }^{5}$
}

${ }^{1}$ Crop Science Division, ICAR Headquarters, Krishi Bhawan, New Delhi -1100 01, India

${ }^{2}$ Department of Crop Improvement, CSK Himachal Pradesh Krishi Vishvavidyalaya, Palampur -176062, India

${ }^{3}$ ICAR-Indian Agricultural Statistics Research Institute, New Delhi - 1100 12, India

${ }^{4}$ ICAR-Sugarcane Breeding Institute, Coimbatore - 6410 07, Tamil Nadu, India

${ }^{5}$ Gobind Ballabh Pant University of Agriculture \& Technology, Pantnagar - 2631 53, India

*Corresponding author

\begin{tabular}{|c|c|}
\hline & A B S T R A C T \\
\hline & \multirow{8}{*}{$\begin{array}{l}\text { Rice bean [Vigna umbellata (Thunb.) Ohwi and Ohashi] is an orphan grain legume, grown } \\
\text { in several parts of the country and has a pivotal role as a pulse in supporting the food } \\
\text { security of the rural poor people, particularly in hill areas. Multipurpose uses and high } \\
\text { nutritional quality of the crop gains its importance in the future food security needs of the } \\
\text { country. Despite many useful characteristics, it has not been subjected to systematic } \\
\text { breeding, hence a study was undertaken to study the diversity of the available germplasm } \\
\text { collected from Himachal Pradesh. In the present study, RAPD markers were employed to } \\
\text { study the genetic diversity, a RAPD profile of } 64 \text { rice bean genotypes generated } 83 \text { bands, } \\
\text { of which } 47 \text { were polymorphic ( } 56.62 \% \text { of polymorphism) with Jacard's similarity } \\
\text { coefficient matrices variation from } 0.48 \text { to } 1.00 \text {. Based on the polymorphism exhibited by } \\
\text { RAPD markers, } 64 \text { rice bean genotypes were grouped into } 2 \text { main clusters which again sub } \\
\text { divided into several sub-clusters. PCA analysis gave the } 12 \text { principal components; among } \\
\text { them first two were accounted for } 61.65 \% \text { of the total variability. A biplot plotted, showed } \\
\text { a positive correlation among all the traits except crude protein with days to fifty percent } \\
\text { flowering and days to fifty percent maturity. Results revealed from the study were } \\
\text { preliminary and can be utilized in rice bean improvement programmes and further } \\
\text { advanced studies. }\end{array}$} \\
\hline & \\
\hline Rice bean, & \\
\hline Vigna, & \\
\hline $\begin{array}{l}\text { RAPD, } \\
\text { Morphometric }\end{array}$ & \\
\hline Article Info & \\
\hline $\begin{array}{l}\text { Accepted: } \\
\text { 30 April } 2017 \\
\text { Available Online: } \\
10 \text { May } 2017\end{array}$ & \\
\hline & \\
\hline
\end{tabular}

\section{Introduction}

Rice bean [Vigna umbellata (Thunb.) Ohwi and Ohashi] is an underutilized grain legume with chromosome number $(2 n=2 x=22)$. Its presumed wild progenitor is $V$. umbellata var. gracilis with which it is cross-fertile (Tomooka et al., 1991). The center of genetic diversity and domestication of rice bean is in Southeast Asia. The wild forms of rice bean are distributed in North-Eastern India, Burma, Thailand, Laos and Vietnam (Ohashi et al., 1988). This non-traditional and underutilized legume has gained attention as supplementary food crop (Gruere et al., 2006). Rice bean seed contains $25 \%$ protein, $0.49 \%$ fat and $5 \%$ fiber. It is also rich in methionine and tryptophan as well as vitamins (thiamine, 
niacin and riboflavin) and restores soil fertility through biological nitrogen fixation (Lohani 1979). It is an important food legume in niche environments and has a pivotal role as a pulse in supporting the food security of the rural poor people, particularly in hill areas. This crop possesses immense potential due to its high nutritional quality, high grain yield and multipurpose usage as food, animal feed, cover crop, green manure and as soil enricher by fixing atmospheric nitrogen (Chaterjee and Dana 1977; Tomooka et al., 2002; Doanh and Tuan 2004). Despite many useful characteristics, it has not been subjected to systematic breeding including disease resistance and the highest potential grain yield among Ceratotropis species (Smartt 1990), and hence little exploited. Thus, there is substantial dearth of scientific studies to assess diversity, use value and marketability.

Knowledge of genetic diversity in a crop species is fundamental to its improvement. It has the evolutionary significance for the survival and adaptation of species in different environments. Traditionally, a variety of morphological and biochemical markers were used to assess diversity based on phenotypic traits, isozymes and protein analysis. Moreover, with the advent of molecular biology techniques, DNA based markers viz. RFLPs, SSRs, RAPDs and AFLPs have played a significant role in species identification and characterization of germplasm. Molecular markers offer plant breeders a set of genetic tools that is abundant, non-deleterious and reliable. Molecular marker system has been successfully used to construct genetic maps, assess genetic diversity and locate genes of interest in a number of agriculturally important crops for the desired traits (Garcia et al., 2005). Among various molecular markers, RAPD is a multi-locus, highly reproducible and rapid method because no prior DNA sequence information is needed for designing PCR primers. Besides being dominant, convenient and allows a larger number of marker to be assayed in short time.

To diversify the primary gene pool of Rice bean accessions, promising genotypes of rice bean were collected from the diverse regions of Himachal Pradesh, Punjab and Uttarakhand. It is expected that the rice bean genotypes from these regions may have economically important adaptive traits that can potentially be incorporated into the rice bean breeding programme for improving disease and pest resistance, nutritional quality and other traits of interest. Therefore, the present study was carried out to assess the level of genetic diversity among sixty-four rice bean genotypes by using morphological and RAPD markers to aid in the selection and efficient utilization of diverse genotypes in improvement of rice bean.

\section{Materials and Methods}

\section{Plant Genetic Materials}

The experimental material for the present study comprised of 64 rice bean genotypes including 4 checks (RBL-1, RBL-6, PRR-1 and PRR-2) collected from the diverse regions of Himachal Pradesh, Punjab and Uttarakhand. These genotypes along with checks were evaluated in alpha lattice design consisting of three replications, eight blocks per replication and eight entries per block. The crop was raised by following standard agronomic practices. Five representative plants in each accession were tagged for recording qualitative and quantitative traits. The present investigation was carried out at Department of Crop Improvement, College of Agriculture, CSK HPKV, Palampur during kharif 2010-11. Different analysis were performed on mean data for each trait using different statistical software viz., principal component analysis, biplot drawing (XLSTAT) and cluster analysis. 


\section{Isolation of Genomic DNA}

Total genomic DNA was extracted from young leaf tissues $(0.5-1 \mathrm{~g})$ collected from randomly selected healthy plants per genotype using CTAB (Cetyl Tri Methyl Ammonium Bromide) method developed by Murray and Thompson (1980) with suitable modifications. The leaf tissues were powdered in liquid nitrogen in autoclaved pre-cooled pestles and mortars. The powder was then transferred to a separate $2 \mathrm{ml}$ centrifuge tubes containing 800 $\mu 1$ of extraction buffer ( $2 \%$ CTAB, $100 \mathrm{mM}$ Tris, $20 \mathrm{mM}$ EDTA, $1.4 \mathrm{mM} \mathrm{NaCl}$ and $1 \%$ PVP, $\mathrm{pH} 8.0$ ) maintained at $60 \mathrm{oC}$ in water bath and mixed gently. The mixture was incubated at $60 \mathrm{oC}$ for $1 \mathrm{hr}$ with intermittent mixing. An equal volume of phenol: chloroform: isoamyl alcohol (25: 24: 1) was added to the tubes followed by gentle mixing. The mixture was centrifuged at 10,000 rpm for 10 minutes at $4 \mathrm{oC}$. The aqueous phase was transferred to fresh tube, followed by addition of $500 \mu \mathrm{l}$ of pre-chilled isopropanol. The contents of the tubes were mixed gently and the mixture was incubated at $-20 \mathrm{oC}$ for 1 hr. DNA was precipitated by centrifugation at $10,000 \mathrm{rpm}$ for 10 minutes using centrifuge. The supernatant was drained and the resulting pellet was washed twice with $1 \mathrm{ml}$ of $70 \%$ chilled ethanol. The pellet was dried in a stream of sterile air in a laminar air flow cabinet. Dried DNA pellet was dissolved in 1 $\mathrm{ml}$ TE buffer $(10 \mathrm{mM}$ Tris- $\mathrm{HCl}, 0.1 \mathrm{mM}$ EDTA, pH 8.0). The dissolved DNA was treated with $1 \mu \mathrm{l}$ of RNase $(10 \mathrm{mg} / \mathrm{ml})$. The quality and concentration of DNA was estimated through electrophoresis using 0.8 per cent agarose gel with known concentration of uncut lambda $(\lambda)$ DNA.

\section{PCR amplification and Gel Electrophoresis}

A total of 15 RAPD primers, each of 10 nucleotides (decamers) primers obtained from M/s Operon Technologies, Alameda, CA,
USA were used for the present study based on their polymorphism, easy to score and distinct fragments (Table-1). For amplification of genomic DNA, a reaction mixture of $12.5 \mu \mathrm{l}$ volume was prepared using $7.15 \mu \mathrm{l}$ of sterilized distilled water, $1.0 \mu \mathrm{l}$ template DNA (25 ng/ $\mu \mathrm{l}), 1.0 \mu \mathrm{l}$ primer, $1.0 \mu \mathrm{l} \mathrm{MgCl} 2$ (25 $\mathrm{mM}), 1.25 \mu 1$ 10x PCR buffer (10 mM Tris$\mathrm{HCl}, 50 \mathrm{mM} \mathrm{KCl}, \mathrm{pH}$ 8.3), $1.0 \mu \mathrm{l}$ dNTP mix $(0.2 \mathrm{mM}$ each of dATP, dGTP, dCTP and dTTP) and $0.1 \mu \mathrm{l}$ Taq polymerase $(3 \mathrm{U} / \mu \mathrm{l})$. The amplification was carried out in an Eppendorf Master cycler with an initial denaturation at $94 \mathrm{oC}$ for 5 minutes, followed by 39 cycles of amplification: 1-minute denaturation at $94 \mathrm{oC}$; 1 -minute annealing at $37 \mathrm{oC}$; 2-minutes extension at $720 \mathrm{C}$. Final extension step was programmed at $72 \mathrm{oC}$ for 5 minutes. The PCR products obtained were stored at $4 \mathrm{oC}$ until the gel electrophoresis was done. PCR products mixed with $2 \mu 1$ of gel loading dye $(0.25 \%$ bromophenol blue and $40 \%$ sucrose), were electrophoretically separated on a $1.8 \%$ agarose gel containing ethidium bromide $(0.5 \mu \mathrm{g} / \mathrm{ml})$ at $100 \mathrm{~V}$ for 90 minutes in $1 \mathrm{x}$ Tris acetate-EDTA (TAE) buffer $(40 \mathrm{mM}$ Tris, $40 \mathrm{mM}$ Acetic acid Glacial, 1 mM EDTA, pH 8.0). The amplified products were visualized and photographed under UV light source using the GelDocumentation Unit (Biovis). The size of amplicons was determined by comparing with DNA ladder (100 bp) with known molecular weight fragments.

\section{Band Scoring and RAPD Analysis}

To analyze the amplified DNA profile of sixty-four rice bean genotypes, the presence or absence of each RAPD band of a particular molecular weight was scored manually. A binary data matrix with ' 1 ' indicating the presence of particular molecular weight and ' 0 ' indicating its absence, was generated separately for each primer. The binary data were used to generate a similarity matrix 
using Jaccard's similarity coefficient (Jaccard 1908) values, $\mathrm{Jij}=\mathrm{Cij} /(\mathrm{ni}+\mathrm{nj}-\mathrm{cij})$, where ' $\mathrm{Cij}$ ' is the number of positive matches between two genotypes, while ni and nj is the total number of band in genotype $i$ and $j$ respectively in SIMQUAL programme of NTSYS-PC package (version 2.02) (Rohlf 1993). Genetic distances (GD) were calculated as GD $=1-[\mathrm{Cij} /(n \mathrm{ni}+\mathrm{nj}-\mathrm{Cij})]$. The data were subsequently used to construct a dendrogram using the Unweighted Pair Group Method with Arithmetical Averages (UPGMA) employing sequential agglomerative hierarchic and non-overlapping (SAHN) clustering program of NTSYS - PC. Different analysis were performed on mean data for each trait using different statistical software viz., principal component analysis, biplot drawing (XLSTAT).

\section{Results and Discussion}

The present study was undertaken to assess the genetic diversity among the rice bean germplasm lines collected from Himachal Pradesh, Punjab and Uttarakhand, understanding the patterns of variation and relatedness among them, and to explore their utilization in the breeding programme for rice bean improvement. Molecular markers have proven to be powerful tools in the assessment of genetic variation and also in the elucidation of genetic relationships within and among the species.

RAPD has been standardized and employed successfully by different workers (Tomooka et. al. 1995; Kaga et.al. 1996; Xu et. al. 2000; Choudhury et. al.; Bora et. al.) to analyze samples of various crops including Vigna species. RAPD profile of 64 rice bean genotypes generated 83 bands, of which 47 were polymorphic $(56.62 \%$ of polymorphism). Each primer gave 3-9 amplification products with an average of 5.53 bands. The RAPD primer OPQ-6 and
OPA-14 generated maximum and minimum number of bands which was found to be 9 and 3 respectively. RAPD primer OPA-19, showed maximum polymorphism (75.00\%) followed by OPI-04 (66.67\%) and OPQ-6 $(66.67 \%)$. The polymorphic band pattern given by primer OPA-19 and OPB-10 is presented in Fig-1 and 2, respectively.

The Jacard's similarity coefficient matrices showed variation from 0.48 to 1.00 (Fig-3). The average similarity across 64 genotypes was found to be substaintially high (0.74). Among the genotypes tested in the study, the rice bean accession PRR-2 was most divergent from rest of the genotypes, which may be due to its different geographical distribution from other genotypes which are mostly from hilly areas. Further, RBL-1 and RBL-6 showed very low dissimilarity as revealed from their inter se similarity coefficient values, they are from the same locations and probably originated from related parents.

\section{Cluster analysis}

Based on the polymorphism exhibited by RAPD markers, 64 rice bean genotypes were grouped into 2 main clusters and cluster $\mathrm{A}$ is further divided in several sub clusters. The genotypes included in different clusters are shown in Table-2 and Fig-3. The genetic similarity between the second clusters was merely 48 per cent.

Cluster A consisted of 63 genotypes whereas cluster B had only one genotype i.e. PRR-2 due to its highly divergent character. Within 6 sub-clusters of A, maximum genotypes were found in sub-cluster AII (41) followed by subcluster AI (7), sub cluster AIV and AVI (5 each), sub-cluster AIII and AV $(3,2)$ respectively. 
Table.1 Number of scorable and polymorphic RAPD bands obtained in the PCR amplified DNA of rice bean genotypes generated by 15 primers

\begin{tabular}{lllcccc}
\hline S.No. & Primer & Sequences (5'-3') & Nf & Np & Nm & Polymorphic bands (\%) \\
\hline 1 & OPI-04 & 5'-CCG CCT AGT C-3' & 6 & 4 & 2 & 66.67 \\
2 & OPI-14 & 5'-TCT GTG CTG G-3' & 4 & 2 & 2 & 50.00 \\
3 & OPA-05 & 5'-AGG GGT CTT G-3' & 5 & 2 & 3 & 40.00 \\
4 & OPA-14 & 5'-TCT GTG CTG G-3' & 3 & 1 & 2 & 33.33 \\
5 & OPA-19 & 5'-CAA ACG TCG G-3' & 4 & 3 & 1 & 75.00 \\
6 & OPB-10 & 5'-CTG CTG GGA C-3' & 8 & 5 & 3 & 62.50 \\
7 & OPO-08 & 5'-CCT CCA GTG T-3' & 4 & 2 & 2 & 50.00 \\
8 & OPQ-06 & 5'-GAG CGC CTT G-3' & 9 & 6 & 3 & 66.67 \\
9 & OPZ-20 & 5'-ACT TTG GCG G-3' & 4 & 4 & 0 & 50.00 \\
10 & OPBA-15 & 5'-GAA GAC CTG G-3' & 5 & 3 & 2 & 60.00 \\
11 & OPBB-06 & 5'-CTG AAG CTG G-3' & 8 & 5 & 3 & 62.50 \\
12 & S-226 & 5'-ACG CCC AGG T-3' & 8 & 3 & 5 & 37.50 \\
13 & S-228 & 5'-GGA CGG CGT T-3' & 6 & 3 & 3 & 50.00 \\
14 & OPBD-09 & 5'-CCA CGG TCA G-3' & 5 & 3 & 2 & 60.00 \\
15 & OPBD-10 & 5'-GAC GCT ATG G-3' & 4 & 1 & 3 & 25.00 \\
\hline \multicolumn{7}{r}{ Mean } \\
\hline \multicolumn{7}{r}{ Total } \\
\hline
\end{tabular}

$N_{f}$ number of fragments; $N_{p}$ - number of polymorphic fragments; $N_{m}$ - number of monomorphic fragment

Table.2 Distribution of rice bean genotypes among different clusters on the Basis of RAPD data

\begin{tabular}{|c|c|c|c|}
\hline Cluster & $\begin{array}{c}\text { Sub } \\
\text { cluster }\end{array}$ & $\begin{array}{l}\text { Number of } \\
\text { Genotypes in } \\
\text { each cluster }\end{array}$ & Genotypes \\
\hline \multirow[t]{6}{*}{$\bar{A}$} & $\overline{A_{I}}$ & 7 & $\begin{array}{llll}\text { RBHP-2, } & \text { RBHP-11, } \\
\text { RBHP-16, RBHP-35 }\end{array}$ \\
\hline & $\mathrm{A}_{\text {II }}$ & 41 & $\begin{array}{l}\text { PRR-1, RBL-1, RBL-6, RBHP-19, RBHP-20, RBHP-22, } \\
\text { RBHP-26, RBHP-31, RBHP-32, RBHP-37, RBHP-39, } \\
\text { RBHP-42, RBHP-43, RBHP-44A, RBHP-44C, RBHP-46, } \\
\text { RBHP-47, RBHP-49, RBHP-53, RBHP-56, RBHP-62B, } \\
\text { RBHP-65, RBHP-66, RBHP-70, RBHP-73, RBHP-74, } \\
\text { RBHP-75, RBHP-76, RBHP-77, RBHP-81, RBH-83, } \\
\text { RBHP-84, RBHP-88, RBHP-89, RBHP-93, RBHP-94, } \\
\text { RBHP-108, RBHP-100, RBHP-111, RBHP-112, RBHP-113 }\end{array}$ \\
\hline & $\mathrm{A}_{\text {III }}$ & 3 & BRS-2, RBHP-17, RBHP-45 \\
\hline & $\mathrm{A}_{\mathrm{IV}}$ & 5 & RBHP-3, RBHP-7, RBHP-62A, RBHP-71, RBHP-72 \\
\hline & $A_{V}$ & 2 & RBHP-23, RBH P-61 \\
\hline & $\mathrm{A}_{\mathrm{VI}}$ & 5 & RBHP-9, RBHP-80, RBHP-86, RBHP-90, RBHP-110 \\
\hline B & & 1 & PRR-2 \\
\hline
\end{tabular}


Table.3 Estimation of Principal component, Eigen value, proportional and Cumulative percent variation

\begin{tabular}{|c|c|c|c|}
\hline Components & Eigen value & Variability (\%) & Cumulative \% \\
\hline P1 & 5.42 & 45.13 & 45.13 \\
\hline P2 & 1.98 & 16.52 & 61.65 \\
\hline P3 & 1.55 & 12.89 & 74.54 \\
\hline P4 & 1.12 & 9.30 & 83.84 \\
\hline P5 & 0.67 & 5.61 & 89.46 \\
\hline P6 & 0.55 & 4.62 & 94.07 \\
\hline P7 & 0.31 & 2.58 & 96.65 \\
\hline P8 & 0.17 & 1.45 & 98.10 \\
\hline P9 & 0.15 & 1.21 & 99.31 \\
\hline P10 & 0.08 & 0.65 & 99.96 \\
\hline P11 & 0.00 & 0.03 & 99.99 \\
\hline P12 & 0.00 & 0.01 & 100.00 \\
\hline
\end{tabular}

Table.4 Estimation of percent contribution of traits for principal component

\begin{tabular}{|l|r|r|r|r|r|r|r|}
\hline & \multicolumn{1}{|c|}{ PC1 } & \multicolumn{1}{c|}{ PC2 } & \multicolumn{1}{c|}{ PC3 } & \multicolumn{1}{c|}{ PC4 } & \multicolumn{1}{c|}{ PC5 } & \multicolumn{1}{c|}{ PC6 } & \multicolumn{1}{c|}{ PC7 } \\
\hline Days to 50\% flowering & 2.054 & 39.573 & 5.434 & 0.435 & 1.944 & 0.261 & 0.056 \\
\hline Days to 75\% Maturity & 2.079 & 39.527 & 5.437 & 0.447 & 1.873 & 0.202 & 0.106 \\
\hline Plant height (cm) & 9.445 & 0.453 & 1.587 & 11.746 & 28.618 & 1.248 & 34.690 \\
\hline Branches/plant & 12.022 & 0.158 & 7.848 & 3.424 & 0.004 & 0.002 & 43.565 \\
\hline Pods/ plant & 10.621 & 1.461 & 19.508 & 0.073 & 0.674 & 0.669 & 0.183 \\
\hline Pod length (cm) & 9.555 & 6.061 & 11.025 & 0.353 & 3.298 & 12.909 & 2.064 \\
\hline Seeds /pod & 9.497 & 2.892 & 12.842 & 2.160 & 1.142 & 24.199 & 0.114 \\
\hline Seed yield /plant (g) & 16.645 & 0.434 & 0.958 & 1.905 & 3.744 & 0.923 & 1.090 \\
\hline 100-Seed weight (g) & 2.079 & 7.479 & 25.946 & 1.979 & 0.187 & 53.288 & 4.556 \\
\hline Crude protein (\%) & 0.908 & 1.526 & 4.705 & 53.565 & 32.797 & 3.894 & 2.226 \\
\hline Biological yield/ plant & 16.236 & 0.414 & 3.962 & 0.631 & 0.116 & 0.159 & 0.002 \\
\hline Harvest Index (\%) & 8.859 & 0.021 & 0.747 & 23.282 & 25.601 & 2.246 & 11.349 \\
\hline
\end{tabular}


Fig.1 RAPD profile in 64 rice bean genotypes using primer OPA-19, $\mathrm{M}=100 \mathrm{bp}$ DNA ladder

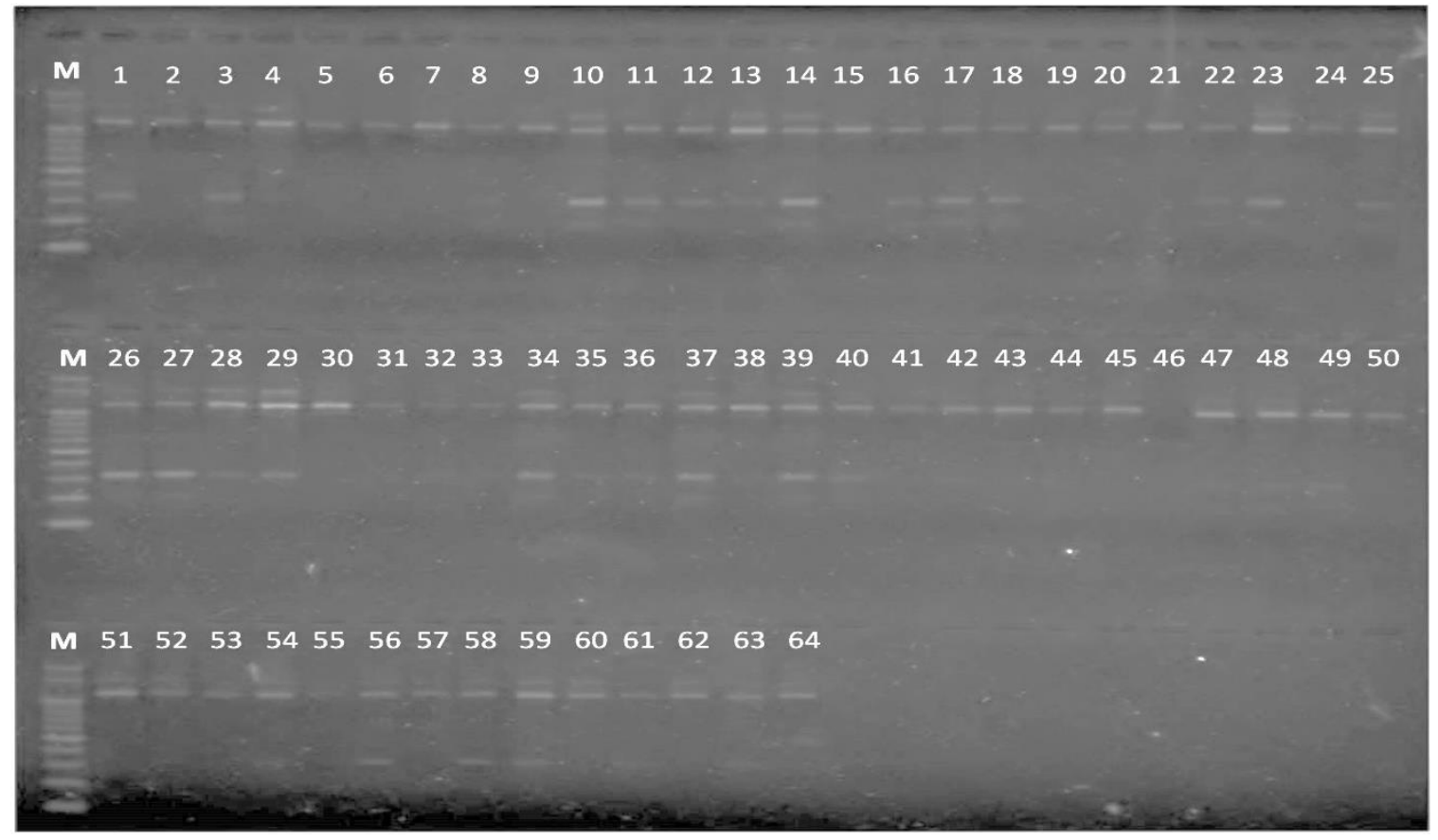

Fig. 2 RAPD profile of 64 rice bean genotypes using primer OPB-10, $\mathrm{M}=100 \mathrm{bp}$ DNA ladder

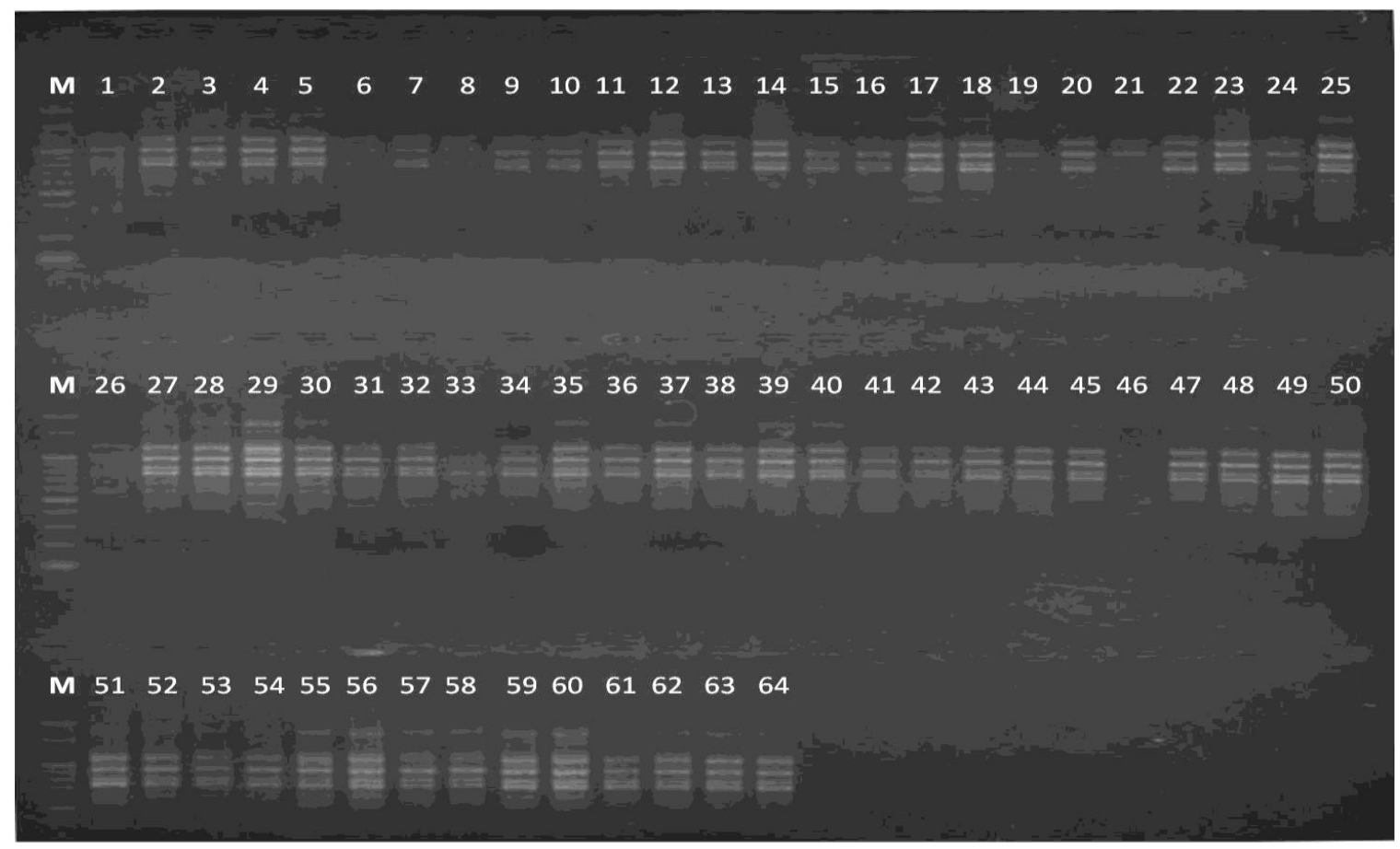


Fig.3 Dendrogram depicting genetic relationships among the rice bean genotypes Constructed using UPGMA method

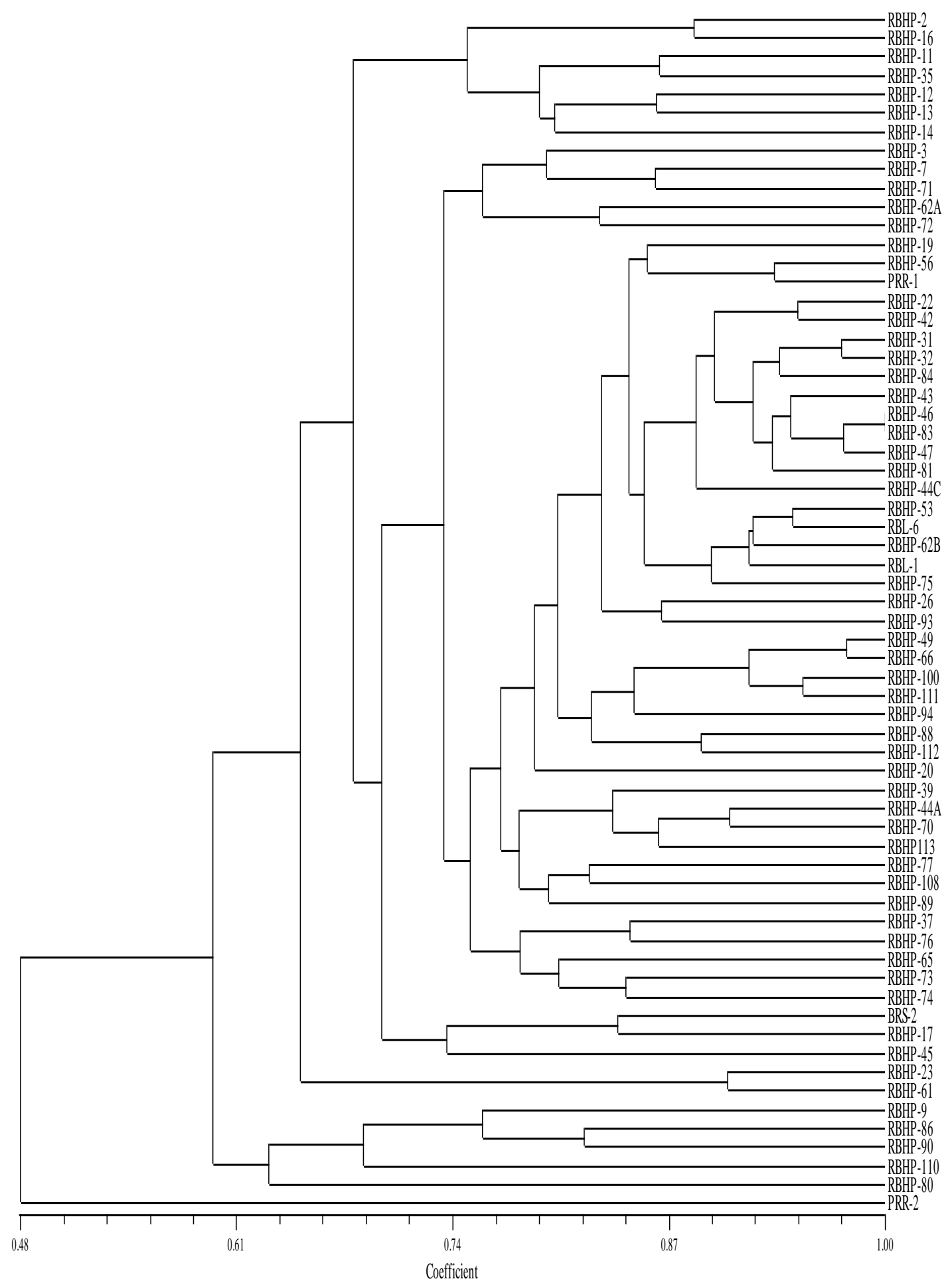


Fig.4 Biplot of 64 rice bean genotypes based on PC1 and PC2

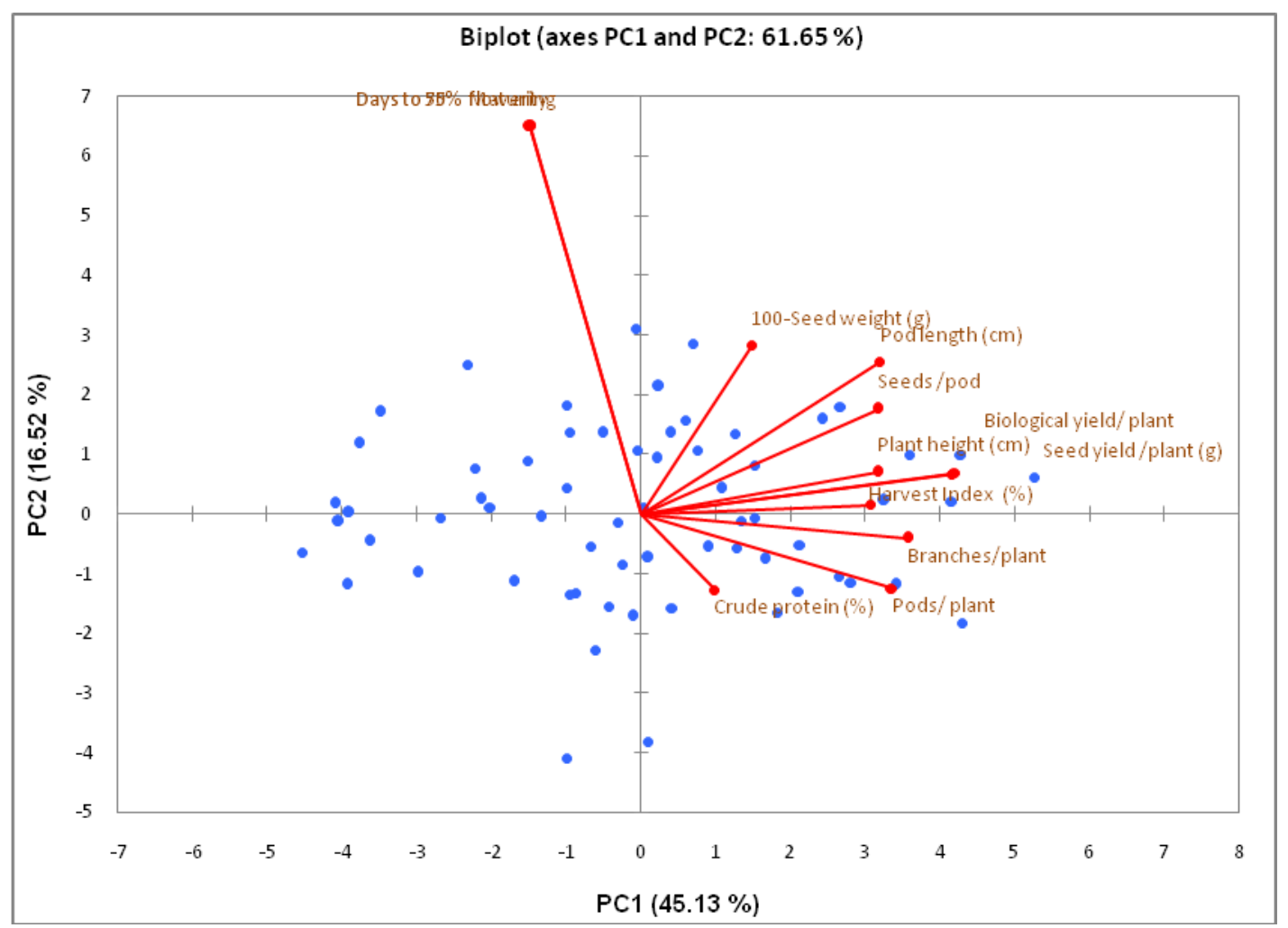

Two genotypes (RBHP-46, RBHP-83) were found to be genetically similar and probably duplicates, since they were collected from nearby locations. Yoon et al., (2007) studied genetic variation and relationships among members of the adzuki bean complex (Vigna angularis) including rice bean ( $V$. umbellata) but was unable to find much polymorphism in rice bean accessions.

In a similar study, Bajracharya et al., (2010) studied genetic diversity among 112 rice bean genotypes using selective simple sequence repeats (SSR) markers developed from adzuki bean ( $V$. angularis) and observed that $35 \mathrm{SSR}$ primer pairs (out of 109) were polymorphic and were used further to characterize genotypes. Muthusamy et al., (2008) also evaluated genetic variation between 10 landraces of rice bean using RAPD and ISSR markers, thus indicated that both the marker systems were equally effective in determining polymorphisms.

Analysis of variance for quantitative traits showed the significant differences among the genotypes for all the quantitative traits. This indicates that sufficient amount of variability was present among the genotypes for all quantitative traits. The 12 principal components were obtained through principal component analysis, out of which 9 explained 99\% of the total variability (Table.3). The First four principal components were accounted for more than $80 \%$ of the total variability and first two were accounted for $61.65 \%$ of the total variability. In principal component analysis, the variance-covariance matrix was used to transform all the quantitative attributes into a single index of similarity in the form of principal component. Most of the variation was distributed up to the 
seventh principal component, being responsible for $94.07 \%$ of the relative variation observed. Examining the Eigen vectors of individual components, level of association with the original traits are indicated. The characters with highest weight in first component were biological yield per plant, seed yield per plant followed by branches per plant, pods per plant, pod length, plant height, and seeds per pod and harvest index (Table-4). Similarly, characters with highest weight in second component were days to $50 \%$ flowering and days to $50 \%$ maturity followed by 100 seed weight. Further, third component, the highest contributor was 100-seed weight and in fourth it was crude protein. Yield and some yield contributing traits appear strongly in the first three components (Katiyar and Dixit 2009). The relationship between different yield contributing traits and genotypes behavior is plotted in the biplot graph (Fig-4). Since, the biplot provides a useful tool for data analysis (Gabriel 1971; Gower and Hand 1996). If the angle and directions between vectors or lines which indicated yield contributing traits are less than $90{ }^{\circ} \mathrm{C}$, it represents a positive correlation and if the angle between the lines is more than $90{ }^{\circ} \mathrm{C}$, it indicates negative correlation. According to the biplot, there was a positive correlation between most of the traits that appeared in graph close to each other except for crude protein with days to fifty percent flowering and days to fifty percent maturity.

It may concluded even though rice bean genotypes were obtained from nearby geographical locations (except for few), $56.6 \%$ polymorphic bands obtained in RAPD indicated it as a potential marker for identification of molecular diversity among rice bean genotypes. Most of the sub-clusters formed in the dendrogram were of genetically more similar genotypes as indicated from their origin. Rice bean being an underutilized but highly potential crop, very few studies have been conducted to assess their genetic relationship and therefore, there is huge scope to obtain their genetic variation through molecular markers like RAPD or preferably by SSRs for further exploration in the crop improvement programme.

\section{References}

Bajracharya, J., Singh, S., Dangol, B., Hollington, P.A. and Witcombe, J.R. 2008. Food Security through Rice bean Research in India and Nepal (FOSRIN): Report 2. Identification of polymorphic markers. Agriculture Botany Division, Nepal Agriculture Research Council and Bangor, Wales, UK, CAZS Natural Resources, College of Natural Sciences, Bangor University. Khumaltar, Nepal.

Bora, A., Choudhury,P.R., Pande, V., and Mandal A.B. 2016. RAPD- Holds Promise to identify Different Genotypes of Rice for use in Breeding Programs of Diverse Genetic Stocks of Rice (Oryza sativa L.) Based on Genetic Diversity. Vegetos. 29(Special): 69-77

Chaterjee, B.N. and Dana, S. 1977. Rice bean [Vigna umbellata (Thunb.) Ohwi and Ohashi]. Tropical Grain Legume Bulletin. 10: 22-25.

Choudhury, P.R., Singh, I.P., George, B., Verma, A.K., and Singh, N.P. 2008. Assessment of genetic diversity of pigeonpea cultivars using RAPD analysis. Biologia Plantarum. 52(4): 648-653.

Doanh, L.Q. and Taun, H.D. 2004. Improving indigenous technologies for sustainable landuse in northern mountainous areas of Vietnam. Journal of Mountain Science, 1: 270-275

Gabriel, F.B. 1971. "The Biplot Graphic display of matrices with application to principal component analysis." Biometrika, 58, 453-467. 
Garcia, G.M., Stalker, H.T., Schroeder, E., Lyerly, J.H. and Kochert, G. 2005. A RAPD-based linkage map of peanut based on a backcross population between the two diploid species Arachis stenosperma and A. cardenasii. Peanut Sciences, 32: 1-8.

Gower, J. and Hand, D. 1996. Biplots. Chapman and Hall, London.

Gruere, G., Giuliani, A. and Smale, M. 2006. Marketing underutilized Plant Species for the Benefit of the Poor: A conceptual Framework. International Policy Research Institute. K Street, NW, Washington, DC, USA

Kaga, A., Tomooka, N., Egawa, Y., Hosaka, K. and Kamijima, O. 1996. Species relationships in the subgenus Ceratotropis (genus vigna) as revealed by RAPD analysis. Euphytica, 88: 1724

Katiyar, P.K. and Dixit, G.P. 2009. Multivariate analysis for genetic divergence in fieldpea (Pisum sativum) germplasm. Indian J. Agri. Sci. 79(3): 181-183.

Lohani, S. 1979. Agricultural crops of Nepal. Published by Devendra Lohani, Maijubahal- Chabahill, and Kathmandu, Nepal. p 282-285

Muthusamy, S. Kanagarajan, S. and Ponnusamy, S. 2008. Efficiency of RAPD and ISSR markers system in accessing genetic variation of rice bean (Vigna umbellata) landraces. Electronic Journal of Biotechnology. 11: 3
Smartt, J. 1990. Evolution and genetic resources. In: Grain legumes. Cambridge: Cambridge University Press, p. 140-175.

Tomooka, N., Lairungreang, C., Nakeeraks, P., Egawa, Y. and Thavarasook, C. 1991. Mungbean and the genetic resources, the Subgenus Ceratotropis. Tropical Agriculture Research Center, Japan.

Tomooka, N., Vaughan, D.A., Moss, H., and Maxted, N. 2002. The Asian Vigna: genus Vigna subgenus Ceratotropis genetic resources. Dordrecht: Kluwer Academic Publishers, pp. 270.

Tomooka, N., Lairungreang, C. and Egawa, Y. T. C. 1995. Taxonomic position of wild Vigna species collected in Thailand based on RAPD analysis. In: Mungbean germplasm. JIRCAS Working Report No. 2: 31-40.

Xu, R.Q., Tomooka, N., Vaughan, A. D. and Doi, K. 2000. The Vigna angularis complex: Genetic variation and relationships revealed by RAPD analysis and their implications for insitu conservation and domestication. Genetic Resources and Crop Evolution. 47: 123-134.

Yoon, M., Lee, J., Kim, C. and Baek, H. 2007. Genetic relationships among cultivated and wild Vigna angularis (Willd.) Ohwi and Ohashi and relatives from Korea based on AFLP markers. Genetic Resources and Crop Evolution. 54: 875-883.

\section{How to cite this article:}

Meena V. S., R. K. Mittal, P. R. Choudhury, S. Rathod, H. K. Mahadevaswamy and Choudhary R. 2017. Utilization of molecular and morphometric tools for assessment of genetic diversity of Rice bean [Vigna umbellata (Thunb.) Ohwi and Ohashi]. Int.J.Curr.Microbiol.App.Sci. 6(5): 2882-2892. doi: http://dx.doi.org/10.20546/ijcmas.2017.605.328 